\title{
Covid-19 in France: Crisis communication and on-the-fly training of populations
}

\author{
Elsa Negre \\ Paris-Dauphine University, PSL Research Universities, CNRS UMR 7243, LAMSADE, 75016 Paris, France \\ elsa.negre@lamsade.dauphine.fr
}

\begin{abstract}
Among the countries of the world, $99.3 \%$ have been affected by the Covid-19 pandemic, which has been raging since the end of 2019 and continues today in 2021. This initially health crisis quickly turned into a pandemic affecting all possible aspects of a crisis (humanitarian, economic, social, etc.). In this article, we are interested in two important aspects of crisis management: communication / dissemination of information and preparing populations for risks. Following interviews with the population, we set an example of the importance of communicating information, preparing populations for future crises and the impact of populations' behaviors.
\end{abstract}

\section{Introduction}

Modern societies are increasingly fragile in the face of crises. To take the example of flooding, the observation was made in particular during the SEQUANA exercise [1] organized in March 2016 by the police headquarters of the city of Paris. This exercise of an almost unprecedented scale in France and in Europe involved several hundred organizations around the simulation of a major flood of the Seine and the Marne for two weeks [1]. This exercise made it possible to compare the consequences of the 1910 flood with those of a similar flood on the same territory and of the same magnitude that would occur in our time in order to draw lessons. A big lesson of this exercise was to note that the social and economic consequences of such a flood would be extremely important today. The proliferation of complex networks, the weakening of interpersonal and intergenerational solidarity, the lack of knowledge of populations on their exposure to risk and their responsibilities in a major crisis situation and metropolitanization are all factors that weaken societies. These observations, which were made at the end of the SEQUANA exercise, can be generalized and are the subject of numerous studies on the vulnerability of populations to face crises [2, 3]. Vulnerability is today at the heart of all studies on risk, as much in the field of biology or physics as in the human sciences. To return to the origins of the term, vulnerability in the biochemical approach refers to the evaluation of potential damage based on criteria of impact, fragility and exposure to risk. It is thus distinguished from so-called "social" approaches which are more focused on the capacity of a society to anticipate hazards, to cope with emergencies, to adapt behavior in times of crisis, and to rebuilt itself [4].

\section{Alerts and common causes of their ineffectiveness during a crisis}

In crisis management, actors have various tools to anticipate and respond to a crisis, including early warning systems (EWS). The particularity of these tools is to help in the resolution of crises of different natures, through the monitoring of hazards by indicators, the risk assessment, the dissemination of alerts, the definition of action plans and the preparing individuals, communities, governments, businesses and other organizations to take appropriate action in the event of an alert to reduce the consequences of a major crisis. Thus, EWS are tools with common characteristics but which can be very different depending on the nature of the crisis for which they have been set up. At last, note that a complete and effective EWS comprises four elements [5]:

- Risk knowledge: knowledge of the relevant hazard and vulnerability;

- Monitoring and warning service: technical capacities to constantly monitor hazard precursors, prediction of potential risks and warning issue;

- Dissemination and communication: dissemination of understandable warnings with prior preparedness information;

- Response capability: knowledge of risks, warning services plans and appropriate actions for persons at risk. 
In this sequential list, each element has two direct links and interactions with each of the other elements. Failure of any part of the system will imply failure of the whole system. Human factor in particular plays a significant and transversal role in all steps [6]. Before and during disasters, people often act according to their own interpretative schemes which are not always adapted to risk situations and can lead to dangerous reactions. Communication technology is a key element in EWS to improve behaviors, it provides common pre-disaster knowledge (before disasters), and guidance to interpret cues during events. The potential influence of communication can be under exploited, for example, warnings are often simplified and reduced to a simple "Red Alert", instead of providing concrete advice and guidance [7].

Although the essential properties of warning systems have been well detailed in the literature and guidelines for setting up effective systems are widely disseminated, operating systems still present certain weaknesses today.

- Taking into account the populations is limited: EWS and/or crisis management systems do not sufficiently involve the populations in the different phases of creation, evolution or activation of the system and do not take sufficient account the different factors that may affect the behavior of populations facing a crisis [5]. Certain so-called community systems go in this direction but they remain in the minority and localized [8].

- Exercises and underused awareness: Exercises linked to alerts are not always organized on a regular basis, and most of the time they are unsuitable for preparing for the unexpected [9]. Generally organized in a partial way (without integrating the populations), they are structured around agreed scenarios and more or less realistic. Exercises are events that always require a lot of investment and a challenge for the actors that some of them fear or even refuse.

- The limits of expertise: Experts have limited knowledge and rationality, they filter the risk according to their perception. On the other hand, the many simulation models that they use in the work of preparing for a crisis are only an imperfect representation of reality, calibrated on the available data, they are often unsuitable for anticipating rare phenomena [10].

- Delays in the decision-making process: The time elapsed between the first signals of a crisis and the moment when the populations are alerted can be very long in relation to the time available to the populations to react. Many of the consequences of the tsunamis, notably the one that occurred in December 2004 in the Indian Ocean, could have been avoided if the decisions to alert had been taken more quickly. Current knowledge now makes it possible to alert populations in time so that they can protect themselves from landslides, floods or tsunamis preceded by earthquakes [11].

- The importance of disinformation (fake news) conveyed by the media: Information is no longer the prerogative of traditional media (television, radio, newspapers). It now uses social networks a lot. The content of information disseminated on social networks is differentiated by its immediacy, its conciseness, and unfortunately the imprecision or even the propagation of false or erroneous information (fake news). Associations are now fighting at the global level so that crisis communication on social networks is very quickly associated with information from official sources or can be deleted by the authorities to put an end to the dissemination of erroneous information. The dissemination of information in social networks and on the Internet is still an issue today. [12] defines the media as a counter-power which has the capacity to influence populations in the short term in their perceptions of risk and their reactions to the alert but which also has longer-term effects on this same perception and on the anticipation of risk by the populations (not to mention the political and economic consequences which are not part of this study) [12].

- Lack of adaptation and creativity: Beyond the definition of well-calibrated procedures and simulations to prepare for a disaster, [13] insists on the importance of developing reflexes and a creative attitude to face a disaster. Very rare are the cases where the predictions of rare events have been proven to be correct. Things never go as planned, and it is often the domino effects that follow a predicted event that turn out to be the cause of events with the most disastrous consequences. This obviously happened in Fukushima in 2011. The earthquake of March 11 recorded off the east coast of Japan caused a tsunami which caused the death of thousands of people and a power failure accompanied by damage to the four reactors of the Fukushima-Daiichi power plant which caused a series of explosions, contamination of water and the formation of radioactive clouds. These consequences in the days which followed the earthquake had very heavy social, economic and political consequences in the longer term at a planetary level. 


\section{Crisis management in France}

The organization of crisis management in France is based on the principle of subsidiarity, it is based on the municipal, departmental and national levels. The decision to trigger the alert falls within the exercise of a general administrative police authority, in accordance with the legal and regulatory provisions in force. The alert is part of a set of measures to protect populations, closely linked to crisis management. During a rescue operation, alerting is one of the responsibilities associated with the direction of rescue operations (DOS). It is, except in exceptional cases, exercised by the Mayor within the framework of his/her powers of general administrative police or by the Prefect ${ }^{1}$. The mayor is the common law authority responsible for making the decision to trigger the alert, in accordance with article L.2212-2-2 of the General Code of Local Authorities. The jurisprudence of the Council of State specifies the field of intervention of the mayor by establishing that it falls to the mayor, under his/her powers of general police, to prepare the crisis situations likely to arise on the territory of his/her commune, and in particular to implement the alert and information measures for the populations (decision of the Council of State of June 22, 1987). The municipal backup plan sets the organization necessary for the dissemination of the alert and safety instructions. The prefect of department also has competence in the matter which intervenes in certain cases (danger on the territory of several communes within the same department, failure of the mayor, event which exceeds the capacities of the commune, event of vast scope that justifies him to take the lead in relief operations). When the prefect is at the origin of the triggering of the alert, the mayor can be brought to supplement its diffusion by all the means/tools at his/her disposal (megaphones, panels with variable message, diffusion of e-mails, etc). Finally, at national level, the Prime Minister (Title III of the Constitution), the Minister of Defence and the Minister of the Interior (Articles L.1142-1 and L.1142-2 of the Defence Code), have the possibility of deciding on the triggering of alert measures. In all consistency, these interventions are generally limited to particularly serious situations concerning a large geographic area. In any event, whatever the authority vested with the power to decide on the alert, the latter is free to choose the vectors of dissemination of this alert. The obligation attached to this mission is an obligation of result, not to resort to particular means/tools.

\footnotetext{
${ }^{1}$ https://en.wikipedia.org/wiki/Administrative_divisions_of_France
}

\subsection{Decision in crisis management}

The urgency of a crisis situation means that the decisions taken to deal with it must be swift and effective. To respond to this, crisis units are set up to bring together the relevant stakeholders. Within a crisis unit, decisions are conditioned by strong uncertainties, a high number of stakeholders, sometimes extremely short periods of time to implement actions, communication problems, and important issues far exceeding the only immediate operational aspects. The decisions mainly concern the choice of actions to be carried out and the resources to be allocated to these actions. They are regularly reassessed according to the evolution of the situation, by a new cycle of questions. An isolated individual is of course not legitimate to make such decisions, even if his/her experience and skills are proven. Decisions are taken collectively, by a multiplicity of stakeholders. Although in the event of a crisis there is a single manager designated as the commander of rescue operations (COS), he/she must interact with interlocutors from different professional cultures, not always present in the same place. According to [14], this multiplicity of stakeholders almost automatically leads to an increase in the possibility of disagreements and delays, and in differences in the hierarchy of priorities. [12] also highlights this difficulty by evoking the growing role that the media play today thanks to the speed with which they have access to information. Their new status as full-fledged actors in the management of the crisis represents a trial that can be "destabilizing" for decision-makers. Finally, decisions are not always consensus.

\subsection{French concrete measures for better integration of populations in crisis response}

The law of August 13, 2004 on the modernization of civil security encourages actions aimed at empowering citizens, going against the paradigm of "all protection" by the state, which, in France, has historically led to the idea that it was possible to protect populations from crises absolutely. This law also proposes to think about the challenges of crisis management in a comprehensive manner. Risks are no longer only considered independently of one another in terms of specific procedures and processes but in a holistic way in relation to the issues associated with them.

Thus, efforts have been made in terms of institutional communication, through an overhaul of the alert system in particular, by the integration of digital tools with an application dedicated to alerting populations (uploaded 
in June 2016), and through increasingly diversified communications on institutional sites, but also on social networks such as Twitter or Facebook more recently. Efforts have also focused on civil security exercises which increasingly include the participation of the populations. For real effectiveness, the consideration of these issues of resilience must be integrated into each stage of crisis management, whether during the phase of prevention, crisis preparation, response, post-crisis and repair. For each of these stages, specific measures must be considered, some of which have started to be implemented in France.

\subsection{French EWS}

The French SAIP alert system (structured set of tools allowing the dissemination of a signal or a message by the authorities) has been the subject of much criticism for several years [15], it is regularly described as "obsolete". The criticisms relate to two major points, (i) the means/tools of warning on the one hand and (ii) educating the populations on the risks to which they are exposed on the other. Concretely, alert has been shown to be ineffective, leading to misinterpretations of signals, failures in the coordination of alert actors, a lack of anticipation or counterproductive or even fatal messages as it has been the case during storm Xynthia which hit France in February 2010.

A Senate report, the Voguel report [15] published in 2017, criticizes precisely the flaws in the current warning system, and in particular the decision taken to continue to favor the national alert network (RNA) considered obsolete; thus involving the renovation of sirens to the detriment of the development of more targeted alert means/tools such as cell broadcasting. The report also calls into question the choices made on the deployment of a smartphone application which must be downloaded beforehand by users, which relies on data transmitted by the internet (unlike cell broadcasting which relies on geolocation) and which needs to be open in the background to be able to broadcast alerts. The application was also abandoned in June 2018 in favor of communication on social networks and major communication channels. But the alert system is not limited to the means/tools of alerting, it also includes all the knowledge relating to the risks, the means/tools enabling the monitoring of the indicators concerned, the action plans and the sensitization of the populations.

However, on this last aspect, the national system is still considered to be faulty. The French population is very poorly aware of the risks to which it is subject and considers itself only weakly involved in the response to be provided in the face of crises [16]; this despite the preventive awareness measures implemented through brochures or information sites. We can also note that these measures are only partially relayed by the local and national media. While efforts are made in terms of institutional communication, on social networks in particular, the French media make very little reference to the behavior to be adopted in the event of an alert or during a crisis. If risk prevention is primarily the responsibility of the public authorities, it also underpins the involvement of each citizen to make prevention policies effective. The accountability of each is enshrined in the law of August 13, 2004 on the modernization of civil security. This text encourages individual commitment to public action which goes against the classic conceptions of civil security which are based on on an institutional preventive approach.

In line with SAIP, the state offered the StopCovid application in order to mitigate the Covid-19 pandemic, but four months after its launch, only $3 \%$ of the population had downloaded the application. This was yet another failure of the applications developed by the state to ensure the safety of citizens. Updated, the StopCovid application has become TousAntiCovid. TousAntiCovid is a mobile contact tracing application deployed in the context of the Covid-19 pandemic in France and initially intended to warn of a possible transmission with an infected person.

\section{Covid-19}

The Covid-19 pandemic is a pandemic of an emerging infectious disease, called coronavirus disease 2019 or Covid-19, caused by the SARS-CoV-2 coronavirus. It appeared on November 16, 2019 in Wuhan, Hubei province (central China), before spreading around the world. The World Health Organization (WHO) first alerts the Republic of China people and its other member states, then declares a state of public health emergency of international concern on January 30, 2020. On March 11, 2020, the Covid-19 epidemic was declared a pandemic by the WHO, which called for essential protective measures to prevent the saturation of intensive care services and to strengthen preventive hygiene (elimination of physical contact, kisses and handshakes, end of crowds as well as unnecessary travel, promotion of hand washing, implementation of quarantine, etc.). To curb the formation of new sources of contagion and preserve the reception capacities of their hospitals, many countries are deciding on containment measures, closing their borders and canceling sporting and cultural events. These decisions have economic, social and environmental consequences and pose uncertainties and 


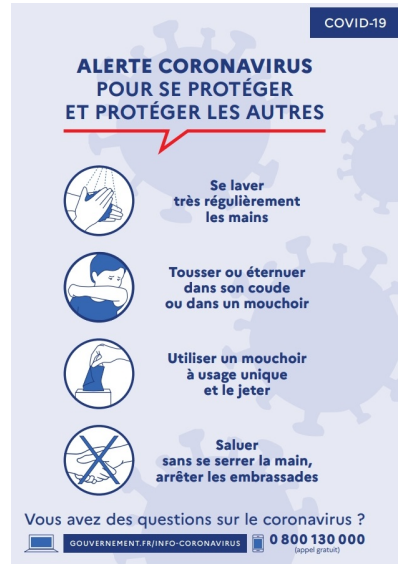

Figure 1: Barrier gestures - March 2020 (Wash your hands very regularly; Cough or sneeze into your elbow or into a tissue; Use a disposable tissue and throw it away; Greet without shaking hands, stop hugging.)

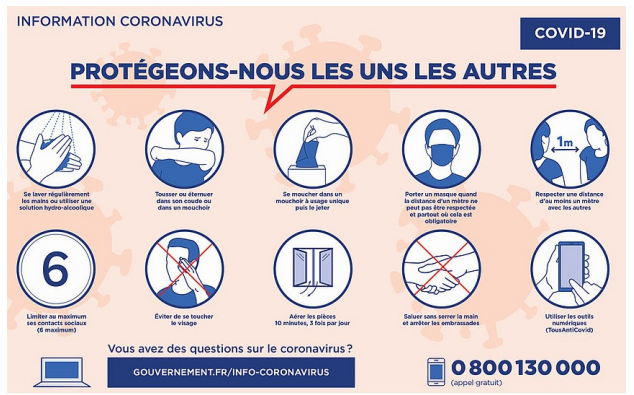

Figure 2: Barrier gestures - June 2021 (Wash your hands regularly or use a hydro-alcoholic solution; Cough or sneeze into your elbow or into a tissue; Use a disposable tissue and throw it away; Wear a mask when the distance of 1 meter cannot be respected and wherever it is required; Maintain a distance of at least 1 meter from others; Limit social contacts as much as possible (6 maximum); Avoid touching your face; Air the rooms for 10 minutes, 3 times a day; Greet without shaking hands, stop hugging; Use digital tools (TousAntiCovid).).

fears on the global economy and on the education, health and fundamental rights of populations.

One of the flagship measures, in addition to the hygienic and social "barrier gestures" (which evolved over the course of the crisis - Figures 1 (March 2020) and 2 (June 2021)), implemented by the French public authorities is the "lockdown", i.e. the ban on movement in France, of the population of March 17, 2020 until May 11, 2020 (two other lockdowns will follow, one in October 2020 and the other in April 2021).

\section{Communication and Preparedness}

In this article, we focus on communicating and preparing people for a crisis. More specifically, we are positioning ourselves in the case of the Covid-19 pandemic which directs us towards emergency

\footnotetext{
${ }^{1}$ https://www.gouvernement.fr/info-coronavirus
}

communication and emergency preparedness (what we call in this article, "on-the-fly training"). It should be noted that in crisis management, the concept of crisis communication is most often used to describe an organization facing a crisis and the need to communicate about that crisis to stakeholders and the public. And (crisis and) emergency risk communication encompasses the urgency of crisis communication with the need to communicate risks and benefits to stakeholders and the public. Emergency risk communication differs from crisis communication in that the communicator is perceived as an agent to resolve the crisis. Each decision must be made within a narrow time constraint, the decision may be irreversible, the outcome of the decision may be uncertain, and the decision may need to be made with imperfect or incomplete information [17]. While the concepts of crisis-preparedness refers to the extent to which the organisation/country is prepared to cope with immediate and future crisis situations [18] and emergency preparedness is related to emergencies: a type of event that produces a range of consequences, and which requires coordinated action, usually urgent and often non-routine [19]. There is therefore an intrinsic link in crisis management between communication and preparedness. So, how is emergency communication relevant to emergency preparedness?

\section{Population interviews}

During the first French lockdown, we tried to interview the population (especially the French population) using a questionnaire. The objective of this study was to obtain, among other things, information on the reactions of people facing the pandemic. The 120 ("open" and "closed") questions in this survey were voluntarily very open to let people express themselves freely, allow them to reflect on their reactions. The study was therefore carried out from an anonymous survey posted online from May 1, 2020 to June 1, 2020. It was created using Google Form ${ }^{2}$ for the creation of online forms and distributed via the Facebook social network and emails (due to the GDPR ${ }^{3}$, we have limited ourselves to our professional mailing lists (many academics and students) and close contacts).

It should be noted that more and more researchers are turning to online survey methods to collect data. The concept of online survey is generally opposed to more conventional/traditional methods of polling by mail, telephone or face-to-face. However, there is no universal definition of what constitutes an online

\footnotetext{
${ }^{2}$ https://www.google.fr/intl/en/forms/about/

${ }^{3}$ General Data Protection Regulation
} 
survey. [20] uses this term to designate surveys where respondents are not only recruited via Internet but must also complete an online questionnaire. [21], for its part, include any survey method involving Internet during the dissemination, sampling or design of the survey. Finally, sometimes the conceptual framework can be ambiguous, as in the case of [22] who defines an online survey as a survey carried out via a website. Like traditional surveys, online surveys must recruit participants. There are two modes of recruitment: (i) probabilistic, where participants are chosen and targeted so that the results are generalizable to a wider population of interest and (ii) non-probabilistic, where the probability that a individual from a population of interest belonging to the sample is unknown [20]. In the case of a probabilistic online survey, it is possible to control the sampling by only distributing the questionnaire to a closed list of email addresses, or by recruiting participants by more traditional methods (phone, face-to-face, etc.) and by providing them with Internet access if necessary to respond to the questionnaire [20, 22]. Conversely, during an online survey with non-probabilistic recruitment, the sampling is not controlled (e.g. invitations to the survey posted on platforms and then relayed via social networks without supervision, etc.). [23] names the latter, which corresponds to our own survey method, "unrestricted self-selection survey" (known as "river sampling"). The use of online survey with non-probabilistic recruitment has many advantages (e.g. decorrelation of survey costs from sample size, reduction of collection times and geographic constraint, etc.) [22] but also disadvantages (e.g. coverage error linked to the digital divide and self-selection of respondents). Many studies, including [24], show that regular users of social networks are hardly representative of the national population. Thus, the use of social media as a dissemination platform can considerably bias the representativeness of a sample of respondents. However, traditional survey methods also come up against problems of coverage and exclusion (e.g. quality of the telephone network, etc.). In all cases, generalizing to a larger population the results of studies obtained from a sample of non-probabilistic respondents requires a precise understanding of the socio-demographic differentiation operated by these different coverage filters. However, in the case of online survey methods using river sampling, these sources seem to be still poorly understood, making the results difficult to generalize and vulnerable to possible misappropriation [20]. To the bias induced by the exclusion of less connected individuals is added the self-selection bias originating from a non-probabilistic recruitment mode. One speaks of self-selection when respondents choose to participate in a survey themselves. It is therefore a frequent occurrence in the survey world, which is not limited to the case of online surveys. The research carried out on this subject present certain points of consensus: the self-selected respondents are more interested in the subject treated than the rest of the population, feel more concerned, and are more likely to have strong opinions concerning the themes of the survey [21, 25]. Unfortunately, if these trends are commonly identified, many authors note that it is difficult to correct the biases induced by uncontrolled voluntary participation [23, 25].

It should be noted that the biases identified in our survey do not impact the quality/validity of the results but give some characteristics of the respondents: people involved who use social media - which is not generalizable.

As part of our online survey with non-probabilistic recruitment, we collected information on the age, sex, professional category and place of residence of the participants, who then answered various questions relating to the information received, the actions carried out, the perception of the alerts, the feelings towards Covid-19, past experiences and their vision of crisis management.

\section{Analysis}

A total of 159 people started to respond to the online survey, 153 answered all questions ${ }^{4}$. Our analysis focuses on these 153 respondents. About $57 \%$ of the respondents are between 25 and 50 years old, $34 \%$ are over 50 years old and only $1 \%$ are less than 25 years old. This low participation of those under 25 may seem unusual since the questionnaire was disseminated via social networks and emails, but perhaps we can partly explain it by the fact that the questionnaire was accessible during the lockdown that the weather was fine and that they were already spending a lot of time on the internet (distance learning, ...); Another reason can also be linked to our "academic" mailing lists. The rest of the population is fairly well represented. This distribution is shown in Figure 3. Furthermore, among the 153 people questioned, 97\% reside in France and, as shown in Figure 3,74\% of respondents hold (at least) a Master's degree. The "high" level of education of the respondents can also be explained by the fact that the questionnaire was distributed by e-mail from academics. Furthermore, Figure 3 shows that men and women are almost evenly distributed (54\% of respondents are women) and Figure 4 that all respondents (regardless of age or sex) are fairly well equipped (95\% have a computer and $87 \%$ a smartphone).

\footnotetext{
${ }^{4}$ France has approximately 67.06 million inhabitants.
} 

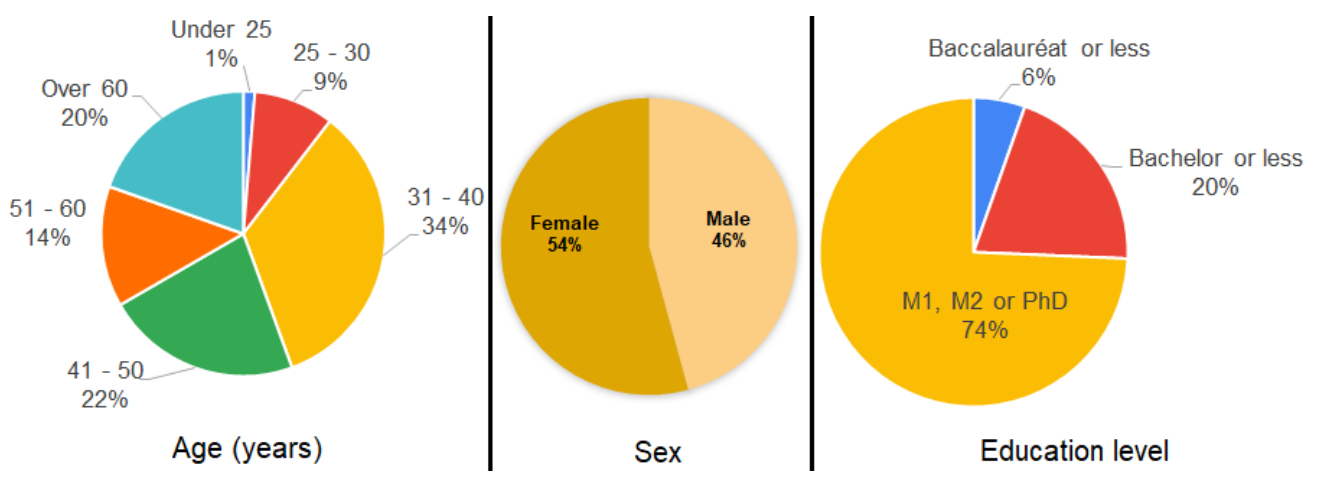

Figure 3: Distribution of respondents

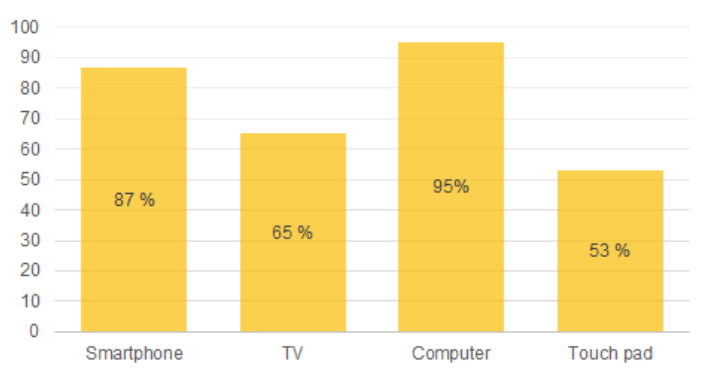

Figure 4: Respondent's devices

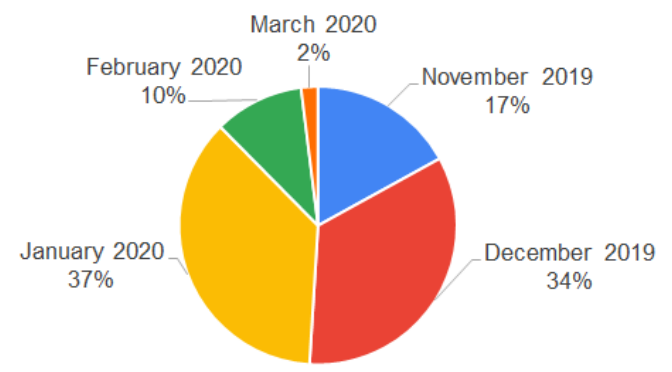

(a) Date respondents first heard of Covid-19.

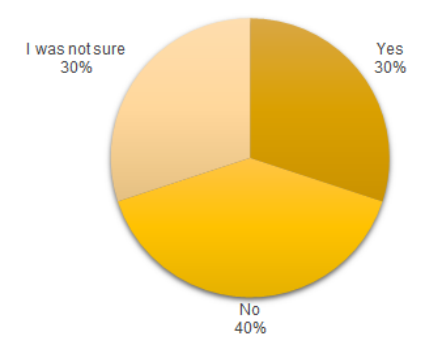

(b) Severity of the situation.

Figure 5: Knowledge of Covid-19 and severity of the situation.

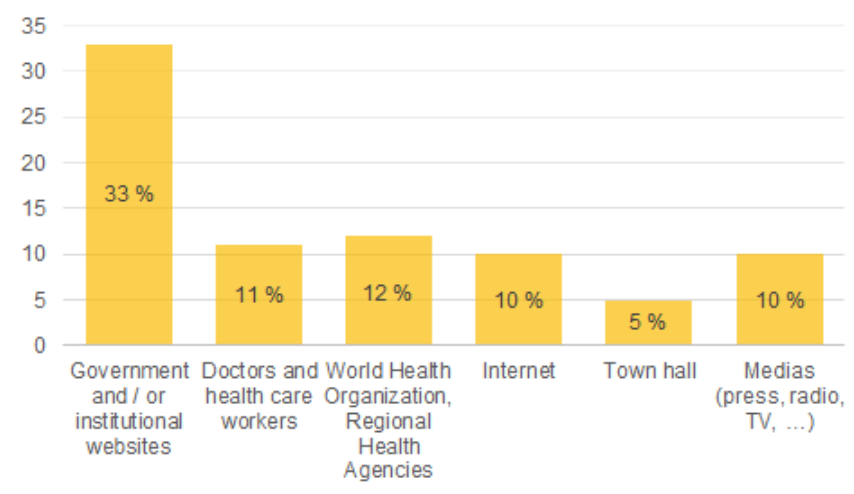

Figure 6: Places to get information. 


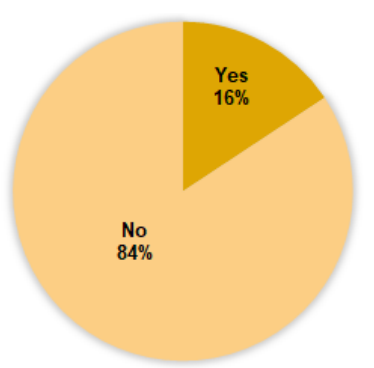

(a) Safety instructions received BEFORE the pandemic (before January 2020).

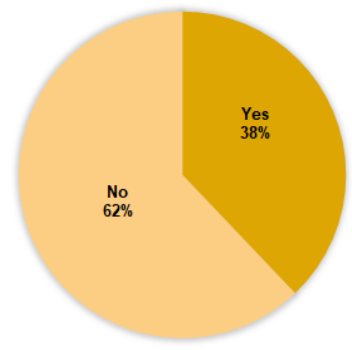

(b) Safety instructions received between February 2020 and early March 2020 (before lockdown in France).

Figure 7: Covid-19 safety instructions received.

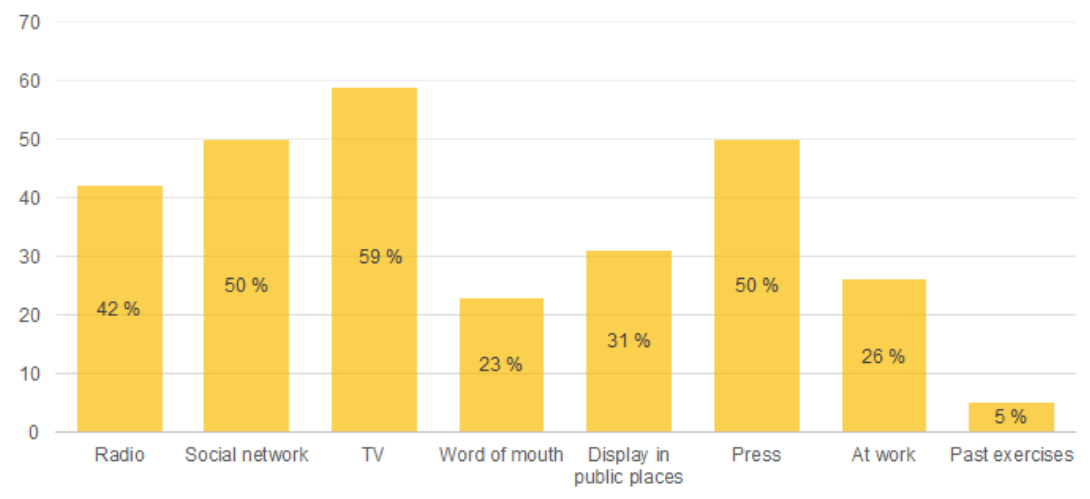

Figure 8: Means/Tools of raising awareness of the behaviors to adopt.

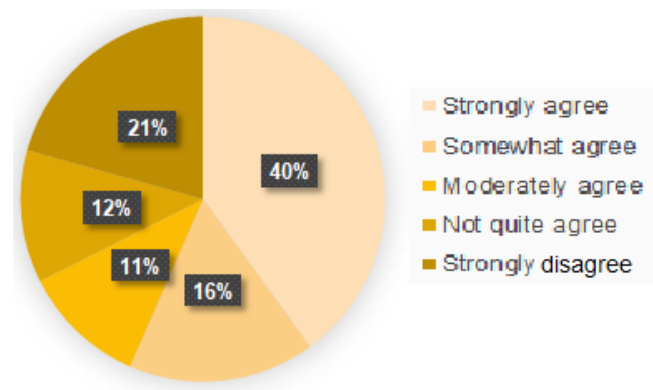

(a) Clarity of instructions.

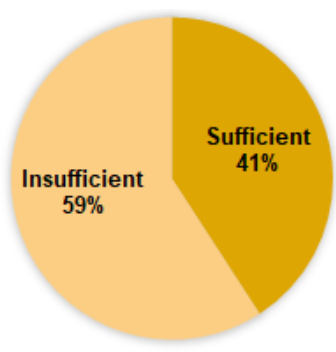

(c) Sufficiency of barrier gestures.

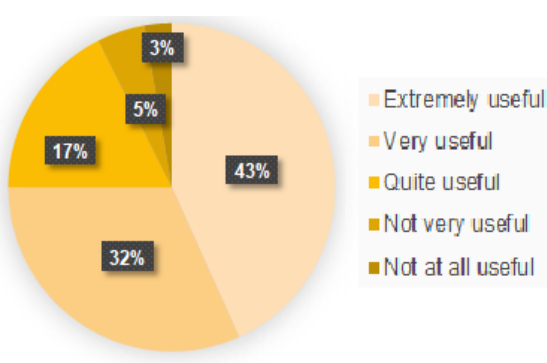

(d) Usefulness of barrier gestures.

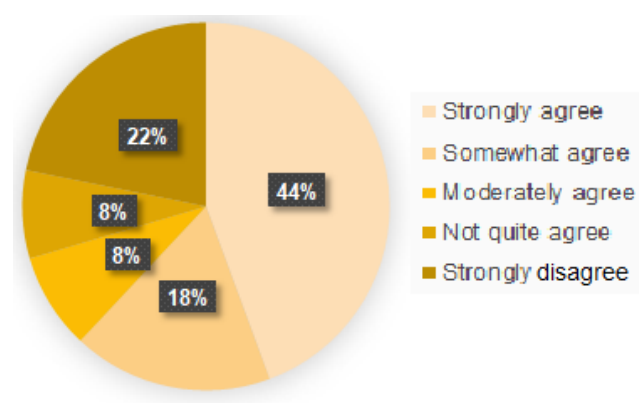

(b) Compliance with instructions.

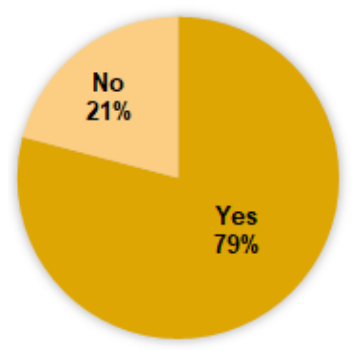

(e) Respect of barrier gestures.

Figure 9: Barrier gestures. 
We are focusing here on a subset of the survey questions. In particular those related to the communication/dissemination of information at the start of a crisis and the preparation of populations facing a health crisis. We have analysed the answers to "closed questions" (Yes/No type questions) as a first step with some descriptive statistics and "open questions" (Wh-questions) syntactically, using the free software IRaMuTeQ ${ }^{5}$.

A first analysis of the terms used in "open" questions reveals that the respondents used the terms information, disinformation (fake news), key figures, communication, barrier gestures, contradictions which show their main concerns about communication but also about decisions taken (sometimes difficult to understand/interpret) and actions/gestures to adopt.

The analysis of the keywords by gender and age of the respondents ${ }^{6}$ showed that, whatever the gender or the age, no keyword is used more than another.

The first cases of Covid-19 patients were detected in China in November 2019. As shown in Figure 5, the majority of respondents only heard about it around December 2019 / January 2020, about 1 month later. Moreover, around $40 \%$ of respondents considered that the situation was not serious. It should be noted that most of them were informed by the traditional media (TV, radio, press) and the Internet. In fact, $80 \%$ of respondents indicate that they know where to find information relating to the crisis and the majority rely on government and institutional websites, see Figure 6.

In addition, Figure 7 shows that $84 \%$ of respondents had not received safety instructions before the start of the pandemic, against 62\% around February / March 2020 , i.e. around 3 months after the first cases.

The majority of respondents were trained and informed of the barrier gestures to be adopted by means of communication at the time of the crisis (TV, Internet, Press). Only 5\% had carried out preparatory exercises (civil security, for example) in the past and had thus been initiated into the actions to be adopted in case of such a crisis, as shown in Figure 8. Finally, 56\% find the safety instructions clear, $62 \%$ find them compliant, $41 \%$ sufficient, $75 \%$ useful and only $79 \%$ respect them, as shown in Figure 9 (respondents over 50 being the most respectful). These last two figures are to be compared. In fact, information on the behaviors to adopt was accessible via many communication channels, surely giving respondents a perception of clarity and compliance, surely encouraging a large majority of them to find the barrier gestures useful and to respect them.

\footnotetext{
${ }^{5} \mathrm{R}$ interface for Multidimensional Text and Questionnaire Analysis. http://www.iramuteq.org/

${ }^{6}$ For the sake of space, all the graphics produced are not exposed in the article.
}

\section{Discussion}

The results of this study are of course specific to the vision of the Covid-19 pandemic by French respondents. It appears that whatever the age, sex and place of residence in France, the expectations/feelings of the respondents are quite the same. We observe that they provide first elements to realize the importance of communication and preparedness of the populations to better accept, understand and respect the decisions of the public authorities during a crisis.

Before the pandemic linked to Covid-19, French respondents thought they were "immune" from a health crisis on French territory and had, for the most part, never asked themselves the question of the actions to be adopted in such circumstances. Unlike other countries, such as Sweden ${ }^{7}$, for example, the French have never received at home or even heard of a booklet / guide on the actions to be adopted in the event of a crisis or war (and if such a document exists in France, there is no large-scale communication).

In fact, during the onset of the Covid-19 pandemic, a large part of the French population was not prepared to face it and the government / institutions had to redouble their efforts, in particular educational communication so that the population can cope. The populations have succeeded in adapting, but better preparation before the crisis, rather than on-the-fly training would have been more effective (more appropriate and faster reactions from the populations and fewer fears, etc.).

In addition, the government's communication could thus have focused on other equally important subjects [26] such as the fight against disinformation (fake news) [27], a better explanation of key figures (which some respondents lacked) and, for example, address remote working/learning issues [28]. Finally, despite numerous academic and operational works on crisis management which promote communication and the preparedness of populations, in reality, on the field, when a crisis occurs, it is clear that many points can still be improved and that, more than ever, populations must be included (as much as possible) in crisis management processes.

\section{Conclusion}

In this article, we are interested in crisis management and, in particular, in the emergency communication and preparedness of the populations. During the first lockdown in France, we were able to interview a part of the French population through an online questionnaire. The analysis of some questions in this questionnaire

\footnotetext{
${ }^{7}$ www.dinsakerhet.se/siteassets/dinsakerhet.se/ broschyren-om-krisen-eller-kriget-kommer/ om-krisen-eller-kriget-kommer-engelska.pdf
} 
relating to communication and preparedness made it possible to highlight the importance of communication (avoid misinformation, reassure, ...) and preparing populations in advance of a crisis (avoid on-the-fly training, misunderstandings, ...). Finally, these are two areas for improvement to be considered for France.

Among the 120 questions of our survey, we have analysed here only 18 of them. A complete analysis will allow us to make some implications and recommendations (for example, regarding the actions of decision-makers or community engagement). Likewise, a comparison and taking a step back from what has been implemented "elsewhere" would be beneficial.

Many lines of research are possible on the basis of our reflection, in particular, on the integration of feedback on a large scale. Finally, further discussion should also be conducted on the information to be disseminated and the means/tools to do so, depending on the target population or the information to be transmitted, as well as how to train/prepare populations. Unfortunately, we are not immune to other large-scale crises occurring in the future.

\section{References}

[1] V. November and L. Créton-Cazanave, La gestion de crise à l'épreuve de l'exercice EU SEQUANA. La Documentation Française, 2017.

[2] W. Donner and H. Rodríguez, "Population composition, migration and inequality: The influence of demographic changes on disaster risk and vulnerability," Social forces, vol. 87, no. 2, pp. 1089-1114, 2008.

[3] J. I. Barredo, "Normalised flood losses in europe: 1970-2006," Natural Hazards and Earth System Sciences, vol. 9, no. 1, pp. 97-104, 2009.

[4] B. Barroca, M. DiNardo, and I. Mboumoua, "De la vulnérabilité à la résilience : mutation ou bouleversement ?," EchoGéo, June 2013.

[5] R. Basher, "Global early warning systems for natural hazards: systematic and people-centred," Philosophical Transactions of the Royal Society of London A: Mathematical, Physical and Engineering Sciences, vol. 364, no. 1845, pp. 2167-2182, 2006.

[6] J. Twigg, The Human Factor in Early Warnings: Risk Perception and Appropriate Communications, pp. 19-26. Springer Berlin Heidelberg, 2003.

[7] T. Comes, B. Mayag, and E. Negre, "Beyond early: Decision support for improved typhoon warning systems," in 12th Proceedings of the International Conference on Information Systems for Crisis Response and Management, May 24-27, 2015., (Krystiansand, Norway), 2015.

[8] A. Collins, N. Maunder, M. McNabb, A. Moorhead, and M. van Aalst, World Disasters Report 2009 - Focus on early warning, early action. International Federation of Red Cross and Red Crescent Societies, 2009.
[9] P. Lagadec, Le continent des imprévus : journal de bord des temps chaotiques / Patrick Lagadec. Entreprises et société, Paris: Manitoba Les Belles Lettres, 2015, 2015.

[10] M. Merad, Aide à la décision et expertise en gestion des risques. 062010.

[11] H. Einstein and R. Sousa, "Warning systems for natural threats," Georisk, vol. 1, no. 1, pp. 3-20, 2007.

[12] P. Lagadec, Preventing Chaos in a Crisis - Strategies for Prevention, Control and Damage Limitation. 1993.

[13] E. Quarantelli, "Disaster crisis management: A summary of research findings," Journal of Management Studies, vol. 25, pp. 373-385, 1988.

[14] J. Pressman and A. Wildavsky, Implementation: How Great Expectations in Washington Are Dashed in Oakland; Or, Why It's Amazing that Federal Programs Work at All, This Being a Saga of the Economic Development Administration as Told by Two Sympathetic Observers Who Seek to Build Morals on a Foundation. Oakland Project series, University of California Press, 1984.

[15] J.-P. Voguel, "Le système d'alerte et d'information des populations : un dispositif indispensable fragilisé par un manque d'ambition," 2017. Rapport sénatorial d'information $\mathrm{n}-595$.

[16] G. Baumont and M.-H. Eljammal, "Analyzing the irsn risk perception barometer over the 1997-2004 period," 2016.

[17] B. Reynolds, J. H. Galdo, L. Sokler, and V. S. Freimuth, "Crisis and emergency risk communication," 2002.

[18] A. Carmeli and J. Schaubroeck, "Organisational crisis-preparedness: The importance of learning from failures," Long Range Planning, vol. 41, no. 2, pp. 177-196, 2008.

[19] W. H. Organization, "A strategic framework for emergency preparedness," 2017.

[20] V. Lehdonvirta, A. Oksanen, P. Rasanen, and G. Blank, "Social media, web, and panel surveys: Using non-probability samples in social and policy research," Policy \& Internet, 2020.

[21] Y.-H. Hwang and D. R. Fesenmaier, "Coverage error embedded in self-selected internet-based samples: A case study of northern indiana," Journal of Travel Research, vol. 42, no. 3, pp. 297-304, 2004.

[22] C. Durand, "Internet polls: New and revisited challenges," 2013.

[23] R. Bigot, P. Croutte, and F. Recours, "Is it possible to extrapolate behaviors of internet-users to the general population?," Cahier de Recherche, CREDOC, vol. C, $273,2010$.

[24] J. Mellon and C. Prosser, "Twitter and facebook are not representative of the general population: Political attitudes and demographics of british social media users," Research \& Politics, vol. 4, no. 3, 2017.

[25] D. Frippiat and N. Marquis, "Web surveys in the social sciences: An overview," Population, vol. 65(2), pp. 285-311, 2010.

[26] M. Marabelli, E. Vaast, and J. L. Li, "Preventing the digital scars of covid-19," European Journal of Information Systems, vol. 30, no. 2, pp. 176-192, 2021.

[27] K. Hartley and K. Vu, "Fighting fake news in the covid-19 era: policy insights from an equilibrium model," Policy sciences, vol. 53, 092020.

[28] A. Ozimek, "The future of remote work," SSRN, 2020. 